\title{
The Development of Visual ATTENTION IN INFANCY
}

\author{
John Colombo \\ Department of Human Development, University of Kansas, Lawrence, \\ Kansas 66045-2133; e-mail: colombo@ukans.edu
}

Key Words infancy, attention, development, cognitive neuroscience, orienting, alertness

- Abstract Over the past decade, the study of attention in infancy has seen dramatic progress. This review delineates four attentional functions (alertness, spatial orienting, attention to object features, and endogenous attention) that are relevant to infancy and uses these functions as a framework for summarizing the developmental course of attention in infancy. Rudimentary forms of various attentional functions are present at birth, but each of the functions exhibits different and apparently dissociable periods of postnatal change during the first years of life. The role of attention in development should therefore be considered in the context of interaction among different systems at different levels of maturity during the first years of life.

\section{CONTENTS}

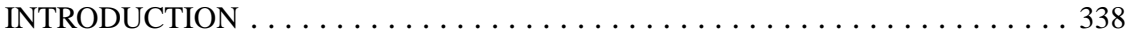

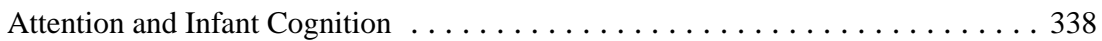

Purpose and Plan of the Review . . . . . . . . . . . . . . . . . . . . . 339

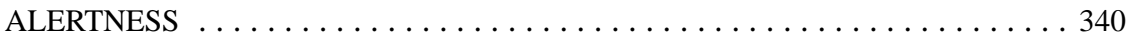

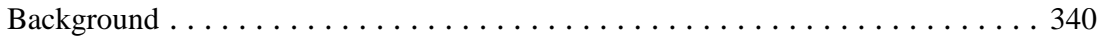

Ascending Brainstem Pathways and Functions Related to Alertness . . . . . . . . . 341

The Development of Alertness . . . . . . . . . . . . . . . . 341

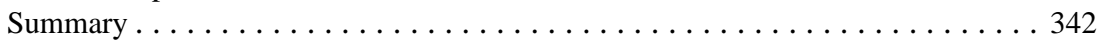

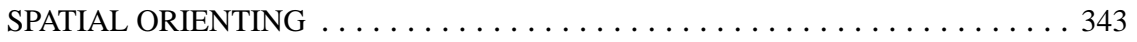

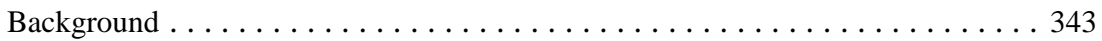

The Components of Spatial Orienting and Their Neural Substrates . . . . . . . . . . 343

The Development of Spatial Orienting . . . . . . . . . . . . . . . . . . . 345

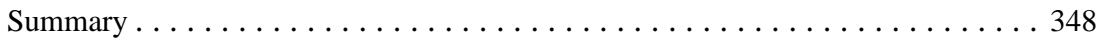

ATTENTION TO OBJECT FEATURES . . . . . . . . . . . . . . . . . . 349

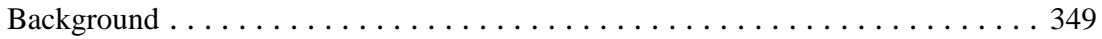

The Neural Substrate of Object Attention . . . . . . . . . . . . . . . . . . . . 349

The Development of Attention to Object Features . . . . . . . . . . . . . . . . . 349 
Summary ....................................... 351

ENDOGENOUS ATTENTION ........................... 351

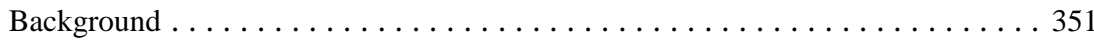

The Substrates of Endogenous Visual Attention . . . . . . . . . . . . . 352

The Development of Endogenous Attention . . . . . . . . . . . . . . . 352

Summary .................................... 355

GENERAL DISCUSSION . . . . . . . . . . . . . . . . . . . . 355

The Developmental Courses of Attentional Functions in Infancy . . . . . . . 355

Varieties of Attention in Infancy: Conclusions and Implications

for Future Research . . . . . . . . . . . . . . . . . . . . . . . 355

\section{INTRODUCTION}

\section{Attention and Infant Cognition}

The study of cognitive development has seen great change and progress over the past three decades, and in many ways the research effort on cognition during human infancy has made significant and considerable contributions to this progress. Such progress is represented within a number of core areas of inquiry, such as sensory (Simons 1993, Werner \& Gray 1998) and perceptual (e.g. Quinn \& Eimas 1996) development, category acquisition (e.g. Madole \& Oakes 1999), memory (e.g. Hartshorn et al 1998), multimodal/cross-modal perception (e.g. Bahrick \& Lickliter 2000), and higher-order reasoning about the properties of objects and space (Baillargeon 1999, Spelke \& Van de Walle 1993).

Such progress represents an impressive record of achievement. It is worth noting, however, that progress in each of these areas is attributable to research paradigms that involve the measurement of infants' visual attention to displays or events. Over the past decade, the topic of visual attention per se in infancy has attracted increasing interest and exposition within the cognitive-developmental literatures (e.g. Burack \& Enns 1997, Atkinson \& Hood 1997, Richards 1998, Ruff \& Rothbart 1996). This proliferation of interest and activity may be attributable to at least two developments in the past decade.

One reason is that interest has grown in the measurement of attention during infancy either as a means to assess of the efficacy of early interventions on cognitive development (e.g. Colombo 1997), or as a means to predict cognitive status in childhood (Colombo \& Mitchell 1990, Rose \& Feldman 1990, Ruff 1990). The observation that early measures of attention were correlated with both concurrent and future indices of cognitive status sparked interest in determining which particular attentional functions were responsible for such continuity from infancy (e.g. Colombo \& Janowsky 1998, Colombo \& Frick 1999, Rose \& Feldman 1995).

A second and perhaps more important influence on the growing interest in infant visual attention has been the emerging influence of cognitive neuroscience on developmental psychology. Visual attention has been one of the primary topics in 
the area of human cognitive neuroscience (e.g. Parasuraman 1998), and progress in that area has readily spilled over into the developmental literatures. Nowhere in the developmental literatures has the influence of cognitive neuroscience been greater than in the study of early development, and nowhere within early development has this approach been more apparent than in the investigation of early attentional processes.

\section{Purpose and Plan of the Review}

The fundamental aim of this paper is to provide an overview and summary of recent advances in the area of visual attention in infancy. Other reviews (Johnson 1995a, 1998; Ruff \& Rothbart 1996) or edited compilations (Richards 1998) on the topic have appeared within the past decade. Some have addressed a limited set of attentional functions; the more comprehensive reviews have been quite lengthy. This review was designed to encompass a breadth of attentional functions and a developmental perspective within a more concise format.

Four Attentional Functions The review begins by drawing a conceptual framework for visual attention that has been guided by recent advances in the field of cognitive neuroscience. In The Principles of Psychology, William James (1890) wrote that "every one knows what attention is." James' confidence notwithstanding, psychologists have since the inception of the field struggled for a satisfactory definition (Moray 1969, 1993). A perusal of the most recent collections of reviews of attention by the foremost scientists in the field (see especially recent collections in Gazzaniga 1995, Parasuraman 1998) finds the definition of attention still elusive. James also referred to the existence of "varieties of attention," and although a century has passed since this characterization, a strong argument can still be made for its validity (see Parasuraman \& Davies 1984). Among the major differences between the turn of the last century and the turn of this one, however, is that the mechanisms and substrates of visual attention are far better understood. Indeed, it is possible to derive a working framework for attentional functions, based on knowledge from studies that have been accumulating on the topic for the past 25 years.

For this review, four particular functions appear to be particularly relevant (see Figure 1). These functions are drawn from several existing theoretical models of visual attention (see Webster \& Ungerleider 1998 for a summary), as well as from aspects of attentional function that appear to be uniquely relevant to early development. In the following sections, each of these functions is explicated with the putative neural substrate that has been identified in the adult. ${ }^{1}$ This is followed

\footnotetext{
${ }^{1}$ There are reasonable indications to support the notion that the neural substrate that mediates a particular behavioral function in adults may be the same neural substrate that mediates the same behavioral function in infancy. However, it is clear that some degree of caution is in order on this point (e.g. Colombo \& Janowsky 1998).
} 


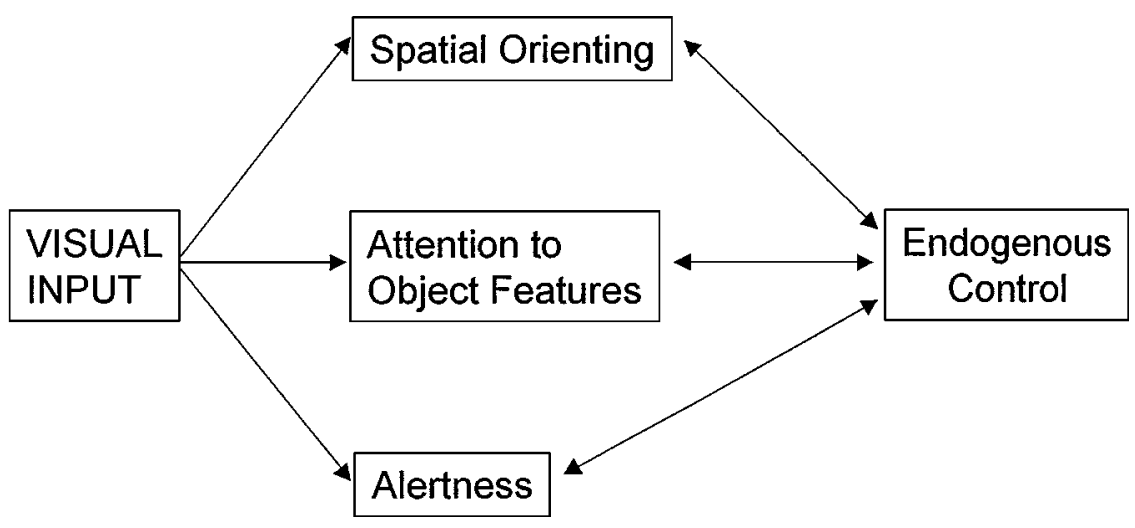

Figure 1 Proposed conceptual framework for the development of visual attention in infancy. Basic components of visual attention considered in the review, along with a fundamental organizational scheme, are considered.

by a review of the available data on the development of that function during infancy.

\section{ALERTNESS}

\section{Background}

In everyday terms, attention may be referred to as a state of preparedness or readiness also known as "alertness." In the adult, psychologists have been mostly interested in the ability to maintain alertness in "sustained attention" or "vigilance" tasks. In such tasks, the maintenance of alertness is presumed to reflect the control of lower-order attentional functions by higher-order attentional structures (e.g. the influence of cortical areas on subcortical structures). As such, the concepts of sustained attention or vigilance fit with the section on endogenous attention below.

However, for the consideration of the development of alertness in infancy, the ability to attain (rather than maintain) the alert state is the more fundamental issue. This is because the attainment of the alert state is not possible until very late in gestation, and is a relatively uncommon event, even at term. Furthermore, it appears that in very young infants (e.g. prior to 2 or 3 months postnatal), an argument can be made that alertness is more readily initiated by exogenous events (e.g. Wolff 1965) or by lower-level mechanisms of arousal (Karmel et al 1991) than by more endogenous ("volitional") sources. As such, it may be that the emergence of the alert state in very young infants (e.g. prior to 3 months postnatal) may be more accurately conceptualized in terms of the ascending influence of subcortical pathways on cortical targets. Because of this particular conceptualization, the development of alertness in infancy is addressed separately in this section rather than with issues of vigilance and sustained attention. 


\section{Ascending Brainstem Pathways and Functions Related to Alertness}

If the attainment of the alert state is a function of subcortical influence on higherorder structures, it makes most sense to start with the brainstem, as brainstem reticular activating systems have been linked to arousal and attention since Morruzzi \& Magoun (1949). Furthermore, it also makes sense to look for ascending pathways from brainstem loci that have been linked with attentional function. Indeed, four pathways ascend from the brainstem to neocortical areas and have been consistently associated with attentional function (Doty 1995, Parasuraman et al 1998, Robbins 1998, Robbins \& Everitt 1995). These ascending pathways are generally characterized as independent entities and identified by their predominant neurotransmitter (noradrenergic, cholinergic, serotonergic, and dopaminergic), although in reality the situation is somewhat more complicated (Doty 1995). The pathways share several common limbic and cortical targets, including frontal areas (Robbins \& Everitt 1995). Although all four pathways may have some role in mediating cognitive function, two of the four ascending pathways appear to be especially involved in this function.

The function of the ascending noradrenergic system may be most closely linked to the notion of anticipatory readiness, or "alertness" for stimulus input. The primary brainstem locus for this system is the locus coeruleus, which is highly active during episodes of behavioral alertness or vigilance (Aston-Jones et al 1994, Rajkowski, Kubiak, \& Aston-Jones 1994, Usher et al 1999), and such activity is correlated with increases in norepinephrine in the cortex (Aston-Jones et al 1991). Marrocco \& Davidson (1998) suggested that locus coeruleus activity is increased during periods when attention is in a state of anticipation of exogenous input, and decreased during periods of high arousal (see Carli et al 1983).

The cholinergic pathway has been implicated in a wide range of cognitive tasks, including sustained attention tasks (Robbins et al 1989, Sahakian et al 1993, Sarter 1994, Warburton 1977). Porges $(1976,1992)$ has suggested that this pathway may mediate the psychophysiological responses associated with sustained attention that have been observed across the life span.

The role of the other two ascending pathways in attention is less clear. The dopaminergic systems appears to be more closely allied with the activation of behavior (Brown \& Robbins 1991, Koob 1992, Phillips et al 1991, Robbins et al 1989). The function of the serotonergic pathway is not well understood (Robbins 1998), although one working hypothesis is that it mediates aspects of behavioral inhibition (Gray 1982; Harrison et al 1997a,b, 1992).

\section{The Development of Alertness}

The best source of data on the development of alertness comes from the research on infant state (Korner 1972, Thoman 1990). 
The Alert State in Young Infants It has been commonly noted that the emergence of well-defined behavioral states is a distinguishing characteristic of gestational age. For example, in premature infants under 30 weeks conceptional age, even the basic sleep-wake states are not particularly distinct; from 30 weeks to term, the sleep and wake states become clearly differentiated, and the waking states themselves become reliably distinguishable (Aylward 1981, Berg \& Berg 1979, Wolff 1965). Indeed, the neonate has been characterized as having six distinct states, including two states of alertness (e.g. Wolff 1965, 1966).

Of particular note is that only a minority of the newborn's time is spent in alert states. It is commonly noted that the newborn spends three-quarters of its time in sleep states, and less than $20 \%$ in alert states (Colombo \& Horowitz 1987). Dramatic changes occur in the distribution and quality of waking and sleeping across the first 3 months of age (Berg \& Berg 1979), and among those changes is a dramatic increase in the amount of time spent in alert states over the first 10-12 postnatal weeks (Gerson 1969, Tronick \& Brazelton 1975, Wolff 1955). By the twelfth postnatal week, periods of alertness have become consolidated, are fairly well entrained with the dark-light cycle, and the infant is commonly observed being able to attain, and perhaps maintain, more and more extended periods of alertness (Berg \& Berg 1979).

Some evidence supports the involvement of the ascending brainstem pathways in alertness. For example, vestibular and tactile stimulation typically induces visual alertness in human newborns (Becker et al 1993, Korner \& Grobstein 1966, Korner \& Thoman 1970). Structures in the ascending noradrenergic pathway are involved in the processing of vestibular input (Nishiike et al 1997, Pompeiano et al 1991, Schuerger \& Balaban 1999), and so it seems possible that stimulation involved in common caregiving activities (picking up or rocking the infant) may produce changes in norepinephrine in any number of higher-order brain areas. Furthermore, it is also the case that newborns' and 1-month-old infants' visual responses to stimuli of different levels of complexity, motion, or novelty are strongly affected by manipulations of arousal, such as feeding or swaddling (Gardner \& Karmel 1981, 1984; Gardner et al 1992; Gardner \& Turkewitz 1982; Geva et al 1999), or by prior stimulation in modalities other than vision (Gardner et al 1986). This is not the case with older infants, however. Such findings fit well with animal work showing that brainstem-mediated functions can modulate transmission of signals in the primary visual pathway (see Doty 1995).

\section{Summary}

The attainment of the alert state is possible in the newborn, but is not a frequent or extended occurrence during the first month. During the first month, alertness is readily elicited by exogenous stimulation and its quality is affected by manipulations that presumably increase or decrease levels of arousal. During the interval from 4 to 8 or 10 weeks postnatal, alertness is attained more frequently and for longer periods, which are increasingly consolidated and entrained with the 
dark-light cycle. It is of some note that early state organization has been shown to relate to later cognitive function within infancy (Colombo et al 1989, Moss et al 1988), and that early state disorganization is a powerful indicant of systemic risk (see Colombo \& Horowitz 1987 for a review).

\section{SPATIAL ORIENTING}

\section{Background}

The concept of selection is an integral component of the classic definitions of attention (e.g. James 1890). Research over the past two decades has clearly indicated that one distinct type of selection involved in human attention involves selection on the basis of the spatial coordinates in the visual field (e.g. Desimone \& Ungerleider 1989). That is, the function of one brain system concerned with attention involves the orienting and shifting of attention to a particular spatial locus.

In reality, it is a matter of some current debate whether visual attention is shifted to a locus, or to a stimulus located at a particular spatial coordinate. Based on the results of several experiments (Egly et al 1994, He \& Nakayama 1995), Driver \& Baylis (1999) have suggested that the posterior system orients visual attention to some "segmented" regions of space rather than to a spatial locus per se. Such a region may be described as a crudely defined "blob" or "patch," although Pylyshyn et al (1994) suggested that more than one region may be involved. It is possible that identification of and orienting to this crudely defined segmented region of the visual field may relate to the kind of "preattentive" search that is observed in feature-positive "pop-out" effects in vision (see Nakayama \& Joseph 1998). In such tasks, visual attention is automatically drawn to particular discrepant elements within a visual display, and detection of such discrepancies is generally unaffected by the number of other elements within the display (Treisman \& Souther 1985).

\section{The Components of Spatial Orienting and Their Neural Substrates}

In any case, spatial orienting can be decomposed into three subfunctions: the engagement of visual attention at a particular stimulus/locus, the disengagement of visual attention from a stimulus/locus, and the shifting of visual attention from one stimulus/locus to another. A "posterior attention system" (e.g. Posner \& Petersen 1990) has been identified as the neural substrate that presumably mediates these functions. The system (sometimes called the "where" system) is composed of three core structures, each of which has been identified with one of the functions listed above. The pulvinar (a nucleus of cells in the thalamus) has been hypothesized to mediate engagement of visual attention to stimuli in particular spatial locations. The posterior parietal lobe mediates disengagement of visual attention from stimuli in such locations (see also Csibra et al 1997). Finally, the superior colliculus mediates the shifting of visual attention from one locus to another. 
Of note is the fact that spatial orienting can be either overt or covert (see, e.g. Posner \& Rothbart 1998). In covert orienting, the effects of an attentional shift can be noted prior to the initiation of an ocular movement to a location. In adults, such covert orienting is thought to be a function of the posterior system. In contrast, overt orienting involves an actual eye movement, and the execution of this response is thought to bring in other (likely frontal) systems that are related to saccade planning and execution.

Spatial-orienting has been indexed by a number of measures. One measure is smooth pursuit, which is a class of continuous, slow, smooth, and automatic eye movements that can only be elicited by the tracking of a target moving across the visual field. Such eye movements are distinct from the class of discontinuous and rapid saccadic movements that are generated either reflexively in response to the appearance of peripheral targets, or endogenously in the course of foveal visual inspection.

Another set of measures is provided by assessments of covert attentional shifts and rapid saccadic eye movements. Reflexive or "express" saccades are made in response to a target that appears abruptly in the peripheral visual field. Such saccades are mediated by some combination of structures and pathways within the posterior, or "where," attentional system described by Posner and others (Posner \& Petersen 1990, Schiller 1998, Webster \& Ungerleider 1998; see also Richards \& Hunter 1998). Covert attentional shifts are typically assessed in paradigms in which a subject's visual attention is "cued" to a spatial location by some visual signal prior to the appearance of a target in that location (Posner 1980). After such cueing, the target usually appears at the cued location (i.e. the cue is valid), but may appear elsewhere (i.e. the cue is invalid). Reaction time is facilitated with valid cues (evidence of a covert attentional shift to the cued location), and slowed by invalid cues (evidence of the need to disengage visual attention from the cued location before moving it to the locus in which the target actually appears).

Furthermore, if the time interval between the target and cue is extended, the response to the appearance of the target is slower to the cued location than it is to a contralateral location. This slowed response is known as inhibition-of-return (Posner et al 1985). It is hypothesized that visual attention is shifted to the cued locus, but during the long interval between cue and target, visual attention is shifted back to midline. When the target eventually appears, the response time to it is believed to be slower because the posterior system tends to resist shifting visual attention back to locations that have been previously attended (e.g. Johnson 1995a).

Finally, disengagement has also been assessed with the gap or competition paradigm. Here, a central visual target is presented prior to the appearance of a target in the periphery. The central target may remain after the peripheral target is presented (overlap/competition condition), may disappear coincident with the appearance of the peripheral target (no-overlap/noncompetition condition), or may be turned off some brief interval prior to the presentation of the peripheral target (gap condition). Time to respond to the peripheral target is slowest under overlap 
conditions (where disengagement is most difficult) and fastest under gap conditions (where disengagement is not necessary).

\section{The Development of Spatial Orienting}

The development of functions involved in orienting to spatial loci is generally revealed through studies of infants' performance on particular marker tasks. These include smooth pursuit, the shifting of visual attention with reflexive or "express" saccadic eye movements, disengagement of attention, and inhibition of return.

Smooth Pursuit Smooth pursuit has been elicited in newborns (Kreminitzer et al 1979, Shea \& Aslin 1990) under conditions in which target speeds are moderately slow and velocity is constant (see Hainline 1998). A rapid improvement in smooth pursuit performance apparently occurs between birth and 3-4 months of age (Aslin 1981, Phillips et al 1997, Von Hofsten \& Rosander 1997). Older infants show more smooth pursuit, fixate moving targets more accurately, and track faster-moving targets more readily (Richards \& Holley 1999) than younger infants. As such, it is likely that the mechanisms mediating smooth pursuit per se are intact and functional early on (Hainline 1998), but that the development of the prevalence and accuracy of smooth pursuit may also be affected by immaturity elsewhere in the visual system (Richards \& Hunter 1998). Especially relevant in this regard is that visual input to the superior colliculus is generally based on the magnocellular pathway of the primary visual system. This pathway, which largely mediates visual sensitivity to motion, develops quite slowly relative to the other (parvocellular) visual pathway (Hickey 1977, Hickey \& Peduzzi 1987). In addition, Richards \& Hunter (1998) suggested that the accuracy of smooth pursuit is affected by interactions with other attentional functions mediated by frontal areas.

Shifting Attention to Visuospatial Loci In addition to smooth pursuit, a number of measures that involve overt and covert shifts of visual attention to particular locations in the visual field are generally part of the spatial orienting functions.

Reflexive Saccades to Peripheral Targets Exogenously driven saccades (presumably controlled by the superior colliculus) are present very early in life (see Bronson 1974; Johnson 1990, 1995a; Johnson et al 1991b). Richards \& Hunter (1998) suggested that they are present from birth. In adults, such saccades involve one long movement to the approximate location of the target, followed by one or two very small saccades that localize the target exactly (e.g. Prablanc \& Jennerod 1975). In infants less than 2 months old, a few studies have reported such saccadic movements to be executed in a series of small, equivalent steps from midline to the target (Aslin \& Salapatek 1975, Salapatek et al 1980). These are called hypometric saccades, and they have the same properties as the main sequence saccades used by adults to move the eyes to within a degree or two of the peripheral target (Ashmead 1984). Such saccades may reflect the degree to which overt shifts of 
visual attention by infants are initiated without a guiding covert shift in young infants. However, it should be noted that there is considerable disagreement over the prevalence of such hypometric saccades in young infants (see Hainline 1998, Hainline et al 1985); the resolution of this controversy will need to precede any speculation about what such saccades may reflect.

Targets of Spatial-Orienting in Infancy As noted above, spatial orienting may be directed toward a crudely defined visual object at a particular spatial location. If such spatial orienting is related to the automatic shift of eye movements to particular types of discrepant elements within visual arrays, then a discussion of the small volume of literature on pop-out effects in infancy is warranted here. This issue has been addressed with infants in both attentional (Catherwood et al 1996a, Colombo et al 1995, Quinn \& Bhatt 1998, Salapatek 1975, Van Giffen \& Haith 1984) and memory (e.g. Gerhardstein et al 1999; Rovee-Collier et al 1996, 1992; see Bhatt 1997, for a review) paradigms.

All of these studies suggest the presence of pop-out-like effects (e.g. asymmetry of feature-positive versus feature-negative effects) by 3 months of age, although Catherwood et al (1996a) did find a decrement in performance as a function of increasing distractors. It should be noted that, even at these ages, the pop-out effects are not particularly strong (e.g. Colombo et al 1995). Two studies report the results of infants' visual attention to obvious discrepancies in visual arrays with infants younger than 3 months, and these results are equivocal. Salapatek (1975) did find that 2-month-old infants' saccades were drawn to discrepant areas within visual arrays, although the nature of the response was affected by the stimulus properties of both the discrepant elements and the distractors (see also Colombo et al 1984). Van Giffen \& Haith (1984) observed that 1-month-olds failed to attend to violations of form continuity in hierarchically constructed forms. In some ways, it is surprising that these effects do not appear in very young infants. However, it should be noted that this trend is consistent with other reports, suggesting that some Gestalt visual effects are not present during the neonatal period (Bertenthal et al 1980, Ghim 1990, Spelke et al 1992, Treiber \& Wilcox 1980) and even in older infants may not be demonstrable except under specific stimulus conditions (e.g. Kellman \& Spelke 1983). If such effects are mediated by low-spatial frequency vision (as intimated by Posner 1995), then this may be due to the relatively slower maturation of the magnocellular visual pathway in infancy (Colombo 1995).

In addition to this work on orienting to static objects or object forms, research has been conducted on the infants' spatial orienting to small moving elements in the peripheral visual field (Dannemiller \& Freedland 1993). This work indicates that there is substantial improvement in such orienting from 6 to 14 weeks of age (Dannemiller 1994). Furthermore, within these ages, the stimulus properties of other elements in the visual field have been shown to affect the probability of such orienting (Dannemiller \& Nagata 1995, Nagata \& Dannemiller 1996). The latter finding suggests the viability of a model for visual orienting based on competition among perceptual entities distributed across the entire visual field 
(Dannemiller 1998, 2000). Although the former finding may simply reflect an age-related improvement in sensitivity to visual motion, this may also be attributable to deficits in the very young infant's ability to distribute visual attention globally across the entire visual field.

Spatial Cueing of Infants' Attention Several studies have examined the effect of spatial cueing on visual attention in 2- through 6-month-old infants. The facilitation of infants' eye movements to a target by a cue prior to the appearance of the target can be taken as evidence of one type of covert attentional shift. Studies of such cueing (Johnson et al 1994; Johnson \& Tucker 1996; Richards 2000a,b) report evidence for covert shifting in infants 4 months or older, whereas Hood et al (1998) have observed facilitation as early as 3 months. Johnson \& Tucker (1996), however, have reported that 2-month-olds' performance in such a task was not strongly facilitated by a cue.

Disengagement of Attention An important component of the spatial orienting system is the ability to disengage attention. Disengagement is a function that has been linked directly to the parietal lobe and/or tempo-parietal junction, based on studies of visual neglect (e.g. Rafal \& Robertson 1995). Data on the development of disengagement in infancy comes from two sources.

Obligatory Looking Through the 1960s and 1970s, researchers on occasion made reference to a pattern of prolonged visual fixation in infants from birth to 2 months old. The essential characteristics of this pattern included the idea that the infant was not truly in control of the fixation, but rather that the looking was held by the stimulus in an "obligatory" (Johnson et al 1991a, Stechler \& Latz 1966) or "tropistic" (Caron et al 1977) fashion, and that the looking was in some way dissociated from actual stimulus processing (Greenberg \& Weizmann 1971, Hopkins \& Van Wulfften-Palthe 1985). Hood (1995) recently recast this fixation pattern as simply a deficiency in disengagement, and has coined the term sticky fixation. Evidence reviewed below bears on the relationship of look/fixation duration and disengagement.

Performance in Overlap/Gap Tasks Attentional disengagement has been measured more directly in a number of published studies with human infants. As described above, such studies use tasks in which a central target is used in conjunction with a peripheral target under overlap, nonoverlap, or gap conditions. The dependent measure is generally the latency of the first saccade to the peripheral target.

As with adults, the latencies of infants' saccades are slowest in overlap conditions and fastest in gap conditions (Csibra et al 1998, Hood \& Atkinson 1993, Matsuzawa \& Shimojo 1997). Young infants tested in these studies are clearly capable of disengaging visual attention from a central stimulus, so the presence of the function is not at issue. At issue, however, is the facility with which 
disengagement occurs, and how this facility changes over the next few months. Most studies have reported that disengagement is more readily observed in older infants than in younger infants (Atkinson et al 1992, Hood \& Atkinson 1993, Matsuzawa \& Shimojo 1997; but see Goldberg et al 1997). Several studies in particular report that a major change in the facility of disengagement occurs sometime between 2 and 4 months of age (Frick et al 1999, Johnson et al 1991b, Hood \& Atkinson 1993). An additional study (Hood et al 1998) observed that 3-month-olds had considerable difficulty with disengagement of attention in overlap conditions.

Inhibition of Return As noted above, if visual attention is cued to a peripheral spatial location and allowed to return to midline, saccades to the previously cued location are slower than to peripheral locations on the opposite side (Posner \& Cohen 1980). This inhibition of return (Posner et al 1985) has been posited to be a manifestation of the posterior system's predisposition to orient to novel loci. Inhibition of return is not seen in patients with lesions to the superior colliculus (Posner \& Cohen 1984), so it is considered to be a function aligned with the posterior system.

All studies on the development of inhibition of return in infancy agree that it is present by 6 months of age (Hood 1993), but at issue are its onset and developmental course. Clohessy et al (1991) reported that it was absent in 3- and 4-month-olds, but inhibition of return has recently been documented in 4-month-olds (Johnson \& Tucker 1996, Richards 2000b), 3-month-olds (Harman et al 1994, Richards 2000a) and in newborns (Valenza et al 1994, Simion et al 1995). Again, stimulus and procedural considerations may be important in resolving the differences here (Ruff \& Rothbart 1996). Valenza et al suggested that the phenomenon may be seen in younger infants only when visual attention is truly shifted to or engaged at the initially cued position, and Harman et al (1994) found it only at smaller eccentricities.

The basic function therefore appears to be present very early, but the developmental course is again at issue. Clohessy et al's (1991) data likely reflect an improvement in inhibition of return after 3 or 4 months of age. In support of this contention, Richards (2000a) recently reported an increase in inhibition of return from 3 to 6 months.

\section{Summary}

The various components within the spatial orienting system appear to have somewhat different developmental courses, but all seem fairly well established by 6 months. Smooth pursuit, which is probably mediated by an interaction of subcortical and cortical systems, can be elicited in neonates. However, it is generally not a robust response during the first months, and progresses readily across the first half-year. Functions related specifically to the subcortical structures of the system (i.e. the superior colliculus), such as reflexive saccades and inhibition of return, have been reported in neonates, but also show sizeable changes from 2 or 
3 months to 6 months of age. Indeed, the coarse parsing of objects involved in the shifting of visual attention does not appear to have a particularly early emergence. Finally, disengagement of attention (which has been linked to posterior parietal cortex) is also present in a rudimentary form very early in life, but appears to show considerable improvement particularly from 2 to 4 months.

\section{ATTENTION TO OBJECT FEATURES}

\section{Background}

The where system (described above) selects and moves visual attention to a spatial locus for foveal inspection. The complementary "what" system involves attentional mechanisms that are involved in the analysis of foveal input and the processing of fundamental visual properties that eventually lead to the identification of patterns and objects (Webster \& Ungerleider 1998).

\section{The Neural Substrate of Object Attention}

This pathway extends from occipital cortex through higher visual areas in the posterior inferior temporal cortex and to inferior temporal cortex. Along this pathway, basic visual properties of the pattern or object at hand are processed independently of one another (e.g. Livingstone \& Hubel 1987). At some point, these features of the patterns or objects are reintegrated. As such, this pathway presumably mediates stimulus discrimination and recognition (Ungerleider \& Mishkin 1982).

It is clear that visual attention to object features cannot be sharply dissociated from visual attention to the location of that object in the visual field (Posner 1995). A current debate in the literature concerns the degree to which object features (form and color are those usually put forth as examples, although size and texture are also sometimes mentioned; Robertson 1998) that are apparently processed independently are re-integrated or "bound" together to form a coherent percept (Treisman \& Gelade 1980; but see Duncan \& Humphreys 1989). It can be argued that the "what" pathways extract the visual properties of the stimulus (e.g. Corbetta et al 1995), whereas the "where" system provides common spatial coordinates through which these properties may be bound. Indeed, bilateral parietal damage spares the ability to identify object features, but impairs visual search for such features in conjunction (Friedman-Hill et al 1995, Robertson et al 1997).

\section{The Development of Attention to Object Features}

In the discussion of the development of object attention (i.e. those processes that lead to object recognition and perception) in infancy, several lines of evidence are considered. One concerns infants' attention and processing of visual features and stimulus compounds. Another concerns infants' visual attention to features and elements that are present within defined stimulus boundaries. Finally, there is a 
small amount of literature that speaks to the independence of the processing of visual features from spatial orienting during infancy, which is considered below.

Infant Processing of Visual Features and Compounds Perhaps the first issue addressed by the empirical field of perceptual development was whether the human newborn was capable of perceiving visual patterns (Fantz 1963). Indeed, studies conducted since that time have documented very early sensitivity to the essential properties of visual stimuli (see, e.g. Slater 1997). Studies of the processing of stimulus compounds during infancy are somewhat less clear. Although infants clearly attend to both color and form (Cohen et al 1971), early reports (Cohen 1973, Cornell \& Strauss 1973) suggested that 4-month-olds process color and form as separable components and not as compounds. More recent reports, however, agree that multidimensional visual stimuli can be perceived in a compound (conjunctive) manner by infants 4 or 5 months old (Bushnell \& Roder 1985, Dannemiller \& Braun 1988, Mundy 1985).

Intrastimulus Attentional Shifts and Whole-Part Processing A sizeable literature on young infants' scanning of visual stimuli exists that dates back to the 1970s (see Ruff \& Rothbart 1996). Because such behavior surely involves multiple attentional systems, it is difficult to justify its inclusion in this review. However, some general points are worth considering. First, infants under the age of 2 months scan visual stimuli less extensively than infants older than 2 months (Leahy 1976, Salapatek 1975; but see Hainline \& Lemerise 1982). Second, it has also been reported that young infants are biased toward scanning the external contours of stimuli (Bronson 1990, Maurer 1983, Maurer \& Salapatek 1976, Milewski 1976), although this external bias is subject to stimulus size (Hainline 1981), motion (Girton 1979), or other aspects of stimulus salience (Ganon \& Swartz 1980).

In any case, much evidence suggests that such scanning patterns (and the distribution of attention that such scanning patterns presumably reflect) affect stimulus identification/recognition performance. For example, infants who scan less extensively perform less well on stimulus recognition probes (Bronson 1991, Jankowsky \& Rose 1997). In addition, it appears that patterns of prolonged look duration from 3 to 6 months are related to less extensive visual scanning; infants who look for longer durations have been shown to rely on local elements or features in visual stimuli for recognition (Colombo et al 1991, 1996; Freeseman et al 1993, Frick \& Colombo 1996).

Object Features and Spatial Mapping in Infancy The final pieces of evidence considered here concern studies that have examined the interaction of spatial and object cues in infancy. In an operant stimulus discrimination paradigm, Colombo et al (1990) trained 3-, 6-, and 9-month-olds to attend to (i.e. look at) colorform compounds (e.g. red circle, green square). The compounds were presented to the right and left of midline, and looking to a "correct" dimension (color, form, or spatial position) produced synchronous auditory reinforcement. Six- and 
nine-month-olds learned to attend to both object and spatial dimensions in immediate tests, and retained them over 5-minute delays. Three-month-olds did not show long-term retention of the object-based cues, however. In a subsequent experiment, object and spatial cues were confounded during training and then dissociated during a test. On the test trial, the two older age groups clearly chose to attend to the object cues over the spatial cue, whereas 3-month-olds showed a strong bias for attending to the spatial cue. Harman et al (1994) have recently interpreted that pattern of results as reflecting the independence (if not differences in the developmental course) of attentional systems that code spatial versus object cues. In support of this, Harman et al (1994) conducted a similar set of studies in which 3-, 6-, and 9-month-old infants were observed orienting to novel objects at novel spatial locations. Location and object novelty were equally attractive to 3-month-olds, but 6- and 9-month-olds responded more strongly to novel visual stimuli than to novel locations.

Finally, Catherwood et al (1996a) manipulated exposure time in an effort to determine the time course of the processing of visual features and their joining as compounds in 5- to 6-month-old infants. They found that primary visual features were encoded after very brief exposures (e.g. $250 \mathrm{msec}$ ), but that the mapping of color to particular spatial locations (i.e. coding of a space/color compound) was observed only after exposure was increased to $2500 \mathrm{msec}$.

\section{Summary}

The fundamental functions that relate to object perception (detection of color and form) are probably present in some rudimentary form at birth. However, as with spatial orienting, it also appears that substantial changes occur in object attention during the interval from 2 months of age to 5 or 6 months of age. During that time, positive evidence for feature binding is observed, and the dominance of object cues/features over spatial cues emerges. The development of intrastimulus shifts may be considered to reflect an interaction between the object and spatial attention systems, and may bear on issues of binding and perception of compound stimuli.

\section{ENDOGENOUS ATTENTION}

\section{Background}

To this point, the systems described have allowed for a visual stimulus to be detected, localized, brought to the fovea, and integrated into a unitary "object." Two critical aspects of attentional function remain to be discussed. One involves the apparently volitional direction of attention as a function of the tasks in which the individual is engaged. Another aspect is the ability to inhibit attention, or "hold" one's attention to the stimulus, event, or task at hand. In some ways, this latter function represents the classic vernacular definition of attention, in that it would seem to relate to commonplace attentional constructs such as attention span, 
perseverance, and distractibility. These functions together can be characterized broadly as endogenous attention in that they conform to the concept of endogenous, or internally directed, attentional functions. ${ }^{2}$

\section{The Substrates of Endogenous Visual Attention}

The evidence strongly suggests that these functions are mediated by frontal areas such as the anterior cingulate (Posner 1995, Posner \& Petersen 1990), the frontal eye fields, and dorsolateral prefrontal cortex (Funahashi et al 1989, 1990; Guitton et al 1985). Directed or voluntary attentional saccadic movements (sometimes labeled executive control) (Parasuraman et al 1998) have been associated with cingulate cortex in the medial frontal areas (Posner 1995, Posner \& Petersen 1990). The maintenance of attention and the inhibition of shifting have also been associated with frontal areas such as the frontal eye fields (e.g. Johnson 1998).

The frontal cortex is among the targets of the four brainstem systems discussed previously (Robbins \& Everitt 1995). As such, the frontal areas can be affected by (for example) lower-level inputs that stimulate the locus coeruleus and in turn result in manifestations of alertness. Furthermore, frontal areas are anatomically linked with the substrates that mediate both spatial orienting and object recognition (Webster \& Ungerleider 1998); as such, the frontal areas presumably exert influence on the functions of either of these systems based on input received from the other systems. Finally, it also appears that the frontal systems project to brainstem structures (Watson et al 1981) and may thus initiate or maintain states of arousal that are endemic to vigilant or sustained attentional states.

\section{The Development of Endogenous Attention}

Evidence from three particular areas of infant cognitive function can be brought to bear on endogenous attentional functions in infancy.

Interstimulus Attentional Shifts and Spontaneous Alternation The first of these areas come from shifts in visual attention in which two simultaneously presented stimuli are alternately inspected. The novelty-familiarization paired-comparison paradigm is a fundamental technique for the study of infant cognition (e.g. Fagan 1971). Here, the infant is exposed ("familiarized") to a stimulus, and then presented with a choice between fixating the familiarized stimulus or a novel one. Most often, such paired stimuli are presented to either side of midline, and infants will alternately fixate the two stimuli. Such interstimulus shifting occurs at a relatively

\footnotetext{
${ }^{2}$ Statements like these are risky because invoking a "voluntary" process without accounting for it in strictly monist (and perhaps mechanistic) terms can be taken to imply the existence of a homunculus (see Posner 1995, p. 620). I acknowledge this difficulty and can merely note that this is a problem yet to be solved, although I also note that it has begun to be addressed conceptually by both cognitive neuroscientists (Posner \& Rothbart 1991) and by progress in the connectionist modeling of metacognitive processes (e.g. Elman et al 1996).
} 
rapid rate (Colombo et al 1990), and the rate is affected by stimulus similarity (Ruff 1975). As a result, intrastimulus shifting has been taken to reflect an active and purposeful comparison of the paired stimuli (Ruff \& Rothbart 1996), and thus fits with the endogenous nature of these forms of attention. Interstimulus shifting is more common and faster in older infants than in younger infants (Bronson 1972, Colombo et al 1988, Harris 1973, Ruff 1975). For example, in paired-comparison tests, lack of interstimulus shifting is four times more likely to be observed in 3-month-olds (Frick et al 2000) than it is at 4 months (e.g. Colombo et al 1991). In addition to changes in the frequency of shifting with age, there is evidence that the quality or nature of shifting may also change. That is, in older infants, shifting may reflect a particular attentional style or strategy. Colombo et al (1988) reported that shift rate was reliable across a one-week test-retest period at 7 months of age, but not at 4 months, where intrastimulus shifting may be more to stimulus or task factors.

Shifting has also been considered within an operant discrimination learning paradigm, in which infants were reinforced for fixating one of two paired stimuli (Colombo et al 1990). As described above, in this study, 3-, 6-, and 9-month-old infants learned to fixate the reinforced dimension. The finding that infants showed a "burst" of alternate fixations on the trial just prior to the attainment of a criterion for learning the discrimination (Colombo et al 1990) is relevant.

A special form of interstimulus shifting is spontaneous alternation, which is a pattern in which the subject systematically alternates the position to which motor responses (reaching or searching) are made across trials. This pattern of responding depends on location memory for the previous choice in guiding the next choice, and on the subject's ability to resist repeating a response to a spatial location when the response to that location has just been previously rewarded. As a result, spontaneous alternation has been taken as a measure of response inhibition in children (Reed et al 1984). Such alternation has traditionally been attributed to the function of higher brain areas, including the hippocampus, thalamus, and the frontal lobes (e.g. Divac et al 1975). Vecera et al (1991) observed that 18-montholds readily showed spontaneous alternation on a reaching task, but 6-month-olds showed virtually none.

Attentional Inhibition and Sustained Attention The second area of research relevant to the development of endogenous visual attention in infancy concerns the ability to inhibit attentional shifts. This has been studied in two ways.

Suppression of Saccadic Eye Movements One means of studying the development of this function has been to use modifications of cueing paradigms and have infants inhibit or suppress saccades to the appearance of peripheral targets. As noted above, frontal cortex is involved in the inhibition of saccades to peripherally appearing stimuli (e.g. Guitton et al 1985). Voluntary suppression of such saccades may be taken as evidence of endogenous attentional function. Such suppression has been demonstrated by having the appearance of the peripheral stimulus serve 
as a cue to the infant that an attractive display will appear at some locus other than the cued one. Four-month-old infants can learn to inhibit orienting to the peripheral target under such conditions (Johnson 1995b, Johnson et al 1994). Furthermore, Gilmore \& Johnson (1995) have presented evidence suggesting that 6-month-olds can delay orienting for up to $5 \mathrm{sec}$ after being cued to look to a particular location. Thus, it seems possible for infants to inhibit a saccadic response to a cue by 4 to 6 months of age.

Assessment of Distraction in Infants Another means of studying this is to use a psychophysiological or behavioral marker of the infant's attentional engagement (e.g. Ruff 1986). This strategy has been used predominantly by Richards (e.g. Richards \& Casey 1991, 1992) in his research program. Infants show robust heart rate deceleration during cognitive tasks. Richards (e.g. 1985a,b) has delineated several distinct phases of attention based on the time course of the deceleration. One of these phases is called sustained attention, and is demarcated by a substantial and maintained heart rate deceleration. It has been argued that this phase is the result of frontal-brainstem interactions that have various autonomic (e.g. cardiac and respiratory) effects (see Richards 1985b, 1987, 1989a, 1994; Richards \& Casey 1991).

Furthermore, sustained attention is thought to represent a period of voluntary attentional engagement, where most (if not all) of infants' information processing takes place (e.g. Richards \& Gibson 1997). This is strongly supported by findings with infants from 3 through 6 months tested under conditions involving dynamic and multimodal stimuli. Infants are far less distractible during periods of sustained attention in both experimental laboratory settings (Richards 1985a, 1987, 1988, 1989b, 1997b; Casey \& Richards 1988) as well as in more naturalistic settings during object manipulation and examination (Lansink \& Richards 1997, Oakes \& Tellinghuisen 1994, Ruff et al 1996, Tellinghuisen \& Oakes 1997). Infants show improved recognition performance if either familiarization or the recognition test is conducted during sustained attention (Richards 1997a; see also Linnemayer \& Porges 1986). Finally, smooth pursuit performance is enhanced under conditions of sustained attention (Richards \& Holley 1999).

The developmental course of sustained attention has not been completely established. Heart rate deceleration has not been definitively established in newborns (Jackson et al 1971), and may not emerge until 6 weeks postnatal (Graham et al 1970; see also Berg \& Berg 1979). Functional assessments of sustained attention have been obtained in infants only as young as 8 weeks (Richards 1989b), and there is considerable evidence that there are significant changes in the amount, depth, and frequency of sustained attention from 3 to 6 months (Richards 1989a, Richards \& Casey 1992). However, changes in sustained attention also occur across the latter half of the first year (Lansink et al 2000, Ruff et al 1992b, 1998), and well into the second and third years (Ruff \& Lawson 1990).

A Vigilance Task for Infants Finally, the construct of sustained attention in the adult is usually synonymous with the construct of vigilance. Ruff et al (1990) 
devised a paradigm for measuring vigilance in infants. Infants viewed an interesting event at a particular place that is repeated after brief but variable $(5-25 \mathrm{sec})$ time intervals. The main measure of vigilance was the maintenance of looking during the inter-event interval. Apparently, the ability to sustain a vigilant state was present in the youngest age group tested (5 months), but the paradigm has not been applied to infants below this age.

\section{Summary}

As with the other attentional systems reviewed, measures that presumably reflect endogenous visual attention show change across infancy. Arguments can be made for the presence of some rudimentary form of endogenous visual attention at birth, but the strong evidence for the emergence of such functions and for considerable postnatal change is present during the latter parts of the first year and beyond. Many of these functions have been successfully documented from about the period starting at 3-6 months and extending into the rest of the first year. Thus, the limited data that exist on the development of endogenous attentional functions in infancy suggest that they have a somewhat later and slower developmental course than other attentional systems reviewed here.

\section{GENERAL DISCUSSION}

\section{The Developmental Courses of Attentional Functions in Infancy}

Figure 2 presents a summary schematic for the development of the attentional functions presented here. Figure 2 suggests that there are at least three important postnatal periods of development with respect to visual attention in infancy. One is a period from term to 2 months, when the development of the alert state takes place. Another takes place from 2 or 3 to about 6 months, during which there are rapid changes in both the spatial orienting and object attention functions. The third is from 5 or 6 months and beyond, during which significant change in endogenous attentional function is observed. It is worth noting that Colombo et al (1999) recently conducted a meta-analysis of look duration from infant habituation and fixation paradigms, and concluded that the look duration follows a "triphasic," or cubic, developmental course. That is, look duration increases from birth to 8-10 weeks postnatal, drops from 3 to about 6 months, and then begins a gradual increase that extends from about 6 months through the second and third years.

\section{Varieties of Attention in Infancy: Conclusions and Implications for Future Research}

The first and perhaps most important conclusion to be drawn from this review is that, in keeping with James' (1890) traditional characterization of attention, 


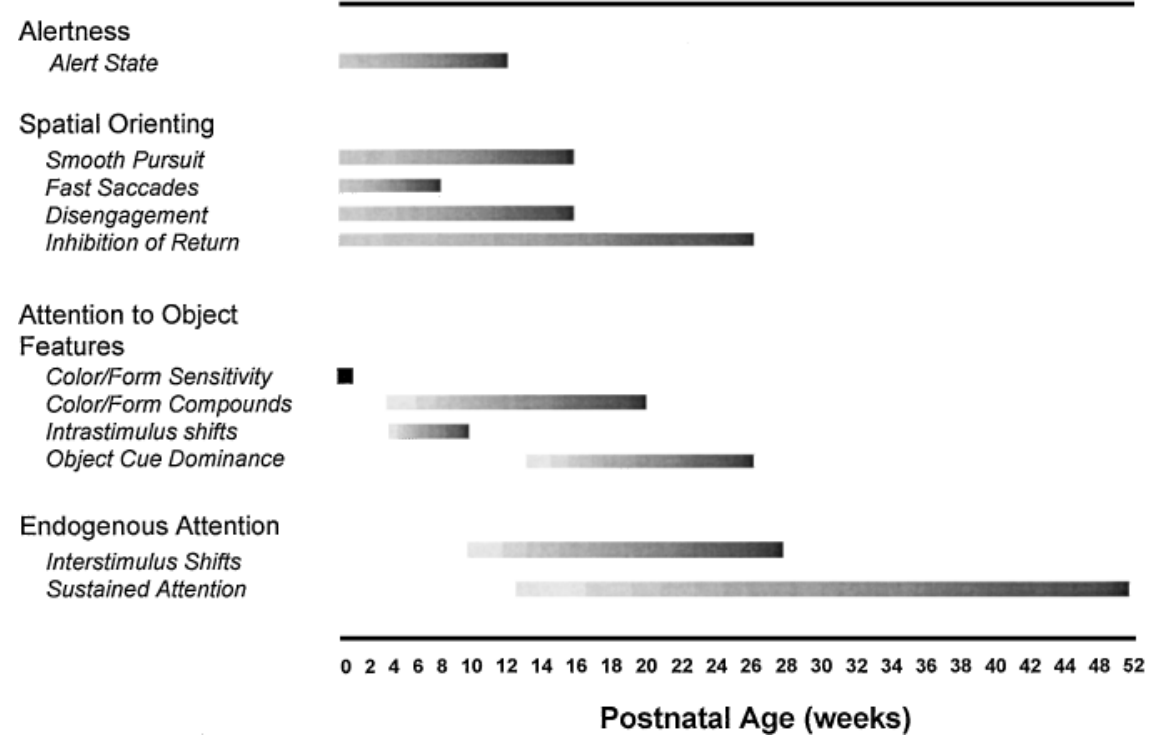

Figure 2 Summary table of the developmental course of visual attentional functions in infancy. The relative darkness of the line indicates the relative degree of maturity at each age for each function as indicated in the literature review.

a variety of attentional forms can be observed and dissociated during infancy. Forms of the attentional functions that have been clearly and reliably documented in the adult appear to exist during the first year of life. Furthermore, the fact that these functions exhibit somewhat different developmental courses adds to the evidence that they are dissociable in infancy as they are in adulthood. In turn, this lends further credence to the possibility that they are subserved by different neural substrates.

Such apparent modularity of visual attention in infancy (see also Colombo \& Janowsky 1998) has important implications for characterizing early attention and for the future of applied research in this area. First, Figure 2 suggests that the assessment of infants' attentional responses to visual stimuli at any one point during the first year will necessarily be the result of an interaction of various systems, with each system at different levels of maturity. Thus, at 8 weeks of age, the infant may have considerable skills in spatial orienting and object attention, but bringing the infant to the alert state will be the primary obstacle in demonstrating those skills. At 16 weeks, attainment of the alert state is generally not such an obstacle, but both spatial and object attention are undergoing rapid developmental change, and endogenous or "controlled" functions might only just be emerging.

The presence of multiple and modular attentional functions also has clear implications for research that seeks to use attentional measures for characterizing current 
or future cognitive outcome. The existence of such varieties of visual attention in infancy clearly implies that no one attentional task or measurement in infancy will account for large amounts of variance in the cognitive status. For research purposes, such modularity implies two alternatives with respect to the choice of attentional measures. First, investigators' choices of specific assessments of infant attention in such studies will need to $(a)$ be guided by a firm theoretical grasp of the type of visual attention that such experiences are expected to affect, or (b) build a wide range of attentional measures into the design of the intervention (e.g. Colombo 1997).

Furthermore, the repeated observation that many (if not all) of these varieties of attention are present in some rudimentary form at birth but develop at different times during infancy suggests that the simple psychometrically based model that has been applied to infant cognition in the past (e.g. Colombo 1993) may no longer be adequate (Colombo \& Saxon 2000). Thus, measurements designed to indicate the presence or absence of attentional functions, or measurement of continuous parameters of attentional functions at a single age point will not serve as the best indicators of early cognitive function. Instead, the optimal assessment of cognitive development in infancy will be more accurately achieved through the measurement and/or modeling of change across periods of rapid development during the first years.

\section{ACKNOWLEDGMENTS}

I am grateful to Steve Fowler for helpful discussions, and to Andrea Greenhoot, Allen Richman, Jill Shaddy, Julie Maikranz, Dale Walker, and especially Janet Frick for comments on an earlier draft. Preparation of this review was supported by NIH grant HD35903.

\section{Visit the Annual Reviews home page at www.AnnualReviews.org}

\section{LITERATURE CITED}

Ashmead D. 1984. Parameters of infant saccadic eye movements. Infant Behav. Dev. 7:16 (Abstr.)

Aslin RN. 1981. Development of smooth pursuit in human infants. See Fisher \& Monty 1981, pp. 31-51

Aslin RN, Salapatek P. 1975. Saccadic localization of visual targets by the very young human infant. Percept. Psychophys. 17:293302

Aston-Jones G, Chiang C, Alexinsky T. 1991. Discharge of noradrenergic locus coeruleus neurons in behaving rats and monkeys suggests a role of vigilance. Progr. Brain Res. 88:501-20

Aston-Jones G, Rajkowski J, Kubiak P, Alexinsky T. 1994. Locus coeruleus neurons in monkey are selectively activated by attended cues in a vigilance task. J. Neurosci. 14:4467-80

Atkinson J, Hood B. 1997. Development of visual attention: bridging disciplines. See $\mathrm{Bu}-$ rack \& Enns 1997, pp. 31-54

Atkinson J, Hood B, Wattam-Bell J, Braddick 
O. 1992. Changes in infants' ability to switch visual attention in the first three years of life. Perception 21:643-53

Aylward G. 1981. The development course of behavioral states in preterm infants: a descriptive study. Child Dev. 52:564-68

Bahrick LE, Lickliter R. 2000. Intersensory redundancy guides attentional selectivity and perceptual learning in infancy. Dev. Psychol. 36:190-201

Baillargeon R. 1999. Infants' understanding of the physical world. In Advances in Psychological Science. Vol. 2. Biological and Cognitive Aspects, ed. M Sabourin, F Craik, pp. 503-29. Hove, UK: Psychol. Press

Becker PT, Grunwald PC, Moorman J, Struhr S. 1993. Effects of developmental care on behavioral organization in very-low-birthweight infants. Nurs. Res. 42:214-20

Berg WK, Berg KM. 1979. Psychophysiological development in infancy: state, sensory function, and attention. In Handbook of Infant Development, ed. JD Osofsky, pp. 28343. New York: Wiley

Bertenthal BI, Campos JJ, Haith MM. 1980. Development of visual organization: the perception of subjective contours. Child Dev. 51:1072-80

Bhatt RS. 1997. The interface between perception and cognition: feature detection, visual pop-out effects, feature integration, and longterm memory in infancy. Adv. Infancy Res. 11:143-91

Bronson GW. 1972. Infants' reactions to unfamiliar persons and novel objects. Monogr. Soc. Res. Child Dev. 373(148): whole issue

Bronson G. 1974. The postnatal growth of visual capacity. Child Dev. 45:873-90

Bronson GW. 1990. Changes in infants' visual scanning across the 2- to 14-week age period. J. Exp. Child Psychol. 49:101-25

Bronson GW. 1991. Infant differences in rate of visual encoding. Child Dev. 62:44-54

Brown VJ, Robbins TW. 1991. Simple and choice reaction time performance following unilateral striatal dopamine depletion. $J$. Neurosci. 9:983-89
Burack JA, Enns JT, eds. 1997. Attention, Development, and Psychopathology. New York: Guilford

Bushnell EW, Roder BJ. 1985. Recognition of color-form compounds by 4-month-old infants. Infant Behav. Dev. 8:255-68

Campbell BA, Hayne H, eds. 1992. Attention and Information Processing in Infants and Adults: Perspectives from Human and Animal Research. Hillsdale, NJ: Erlbaum

Carli M, Robbins TW, Evenden JL, Everitt BJ. 1983. Effects of lesions to ascending noradrenergic neurons on performance of a 5-choice serial reaction task in rats: implications for theories of dorsal noradrenergic bundle function based on selective attention and arousal. Behav. Brain Res. 9:36180

Caron AJ, Caron RJ, Minichiello MD, Weiss SJ, Friedman SL. 1977. Constraints on the use of the familiarization-novelty method in the assessment of infant discrimination. Child Dev. 48:747-62

Casey BJ, Richards JE. 1988. Sustained visual attention in young infants measured with an adapted version of the visual preference paradigm. Child Dev. 59:1514-21

Catherwood D, Skoien P, Green V, Holt C. 1996a. Assessing the primary moments in infant encoding of compound visual stimuli. Infant Behav. Dev. 19:1-11

Catherwood D, Skoien P, Holt C. 1996b. Colour pop-out in infant response to visual arrays. Br. J. Dev. Psychol. 14:315-26

Clohessy AB, Posner MI, Rothbart MK, Vecera SP. 1991. The development of inhibition of return in infancy. J. Cogn. Neurosci. 3:34550

Cohen LB. 1973. A two-process model of infant attention. Merrill-Palmer Q. 19:157-80

Cohen LB, Gelber E, Lazar M. 1971. Infant habituation and generalization to repeated visual stimulation. J. Exp. Child Psychol. 11:379-89

Colombo J. 1993. Infant Cognition: Predicting Later Intellectual Functioning. Newbury Park, CA: Sage 
Colombo J. 1995. On the neural mechanisms underlying individual differences in infant fixation duration: two hypotheses. Dev. Rev. 15:97-135

Colombo J. 1997. Individual differences in infant cognition: methods, measures and models. In Developing Brain and Behavior: The Role of Lipids in Infant Formulas, ed. J Dobbing, pp. 339-72. London: Academic

Colombo J, Fagen JW, eds. 1990. Individual Differences in Infancy: Reliability, Stability, Prediction. Hillsdale, NJ: Erlbaum

Colombo J, Frick JE. 1999. Recent advances and issues in the study of preverbal intelligence. In Development of Intelligence, ed. M Anderson, pp. 43-71. London: Univ. Coll. London Press

Colombo J, Frick JE, Ryther JS, Gifford JJ. 1996. Individual differences in infant visual attention: four-month-olds' recognition of forms connoted by complementary contour. Infant Behav. Dev. 19:113-19

Colombo J, Harlan JE, Mitchell DW. 1999. Look Duration in Infancy: Evidence for a Triphasic Developmental Course. Presented at Soc. Res. Child Dev., Albuquerque, NM

Colombo J, Horowitz FD. 1987. Behavioral state as a lead variable in neonatal research. Merrill-Palmer Q. 33:423-38

Colombo J, Janowsky J. 1998. A cognitive neuroscience approach to individual differences in infant cognition. See Richards 1998, pp. 363-91

Colombo J, Laurie C, Martelli T, Hartig B. 1984. Stimulus context and infant orientation discrimination. J. Exp. Child Psychol. 37: 576-86

Colombo J, Mitchell DW. 1990. Individual and developmental differences in infant visual attention. See Colombo \& Fagen 1990, pp. 193-227

Colombo J, Mitchell DW, Coldren JT, Atwater JD. 1990. Discrimination learning during the first year of life: stimulus and positional cues. J. Exp. Psychol.: Learn. Mem. Cogn. 16:98-109
Colombo J, Mitchell DW, Coldren JT, Freeseman LJ. 1991. Individual differences in infant attention: are short lookers faster processors or feature processors? Child Dev. 62:124757

Colombo J, Mitchell DW, Horowitz FD. 1988. Infant visual attention in the pairedcomparison paradigm: test-retest and attention-performance relations. Child Dev. 59:1198-210

Colombo J, Moss MM, Horowitz FD. 1989. Neonatal state profiles: reliability and shortterm prediction of neurobehavioral status. Child Dev. 60:1102-10

Colombo J, Ryther JS, Frick JE, Gifford JJ. 1995. Visual pop-out in infants: evidence for preattentive search in 3- and 4-month-olds. Psychonom. Bull. Rev. 2:266-68

Colombo J, Saxon T. 2000. Infant attention and the development of cognition: Does the environment moderate continuity? In Infant Development: Ecological Perspectives, ed. H Fitzgerald, K Karraker, T Luster. Washington, DC: Garland. In press

Corbetta M, Shulman GL, Miezin FM, Petersen SE. 1995. Superior parietal activation during spatial attention shifts and visual feature conjunction. Science 270: 802-5

Cornell LB, Strauss MS. 1973. Infants' responsiveness to compounds of habituated visual stimuli. Dev. Psychol. 9:73-78

Csibra G, Johnson MH, Tucker LA. 1997. Attention and oculomotor control: a highdensity ERP study of the gap effect. Neuropsychologia 35:855-65

Csibra G, Tucker LA, Johnson MH. 1998. Neural correlates of saccade planning in infants: a high-density ERP study. Int. J. Psychophys. 29:201-15

Dannemiller JL. 1994. Reliability of motion detection by young infants measured with a new signal detection paradigm. Infant Behav. Dev. 17:101-5

Dannemiller JL. 1998. A competition model of exogenous orienting in 3.5-month-old infants. J. Exp. Child Psychol. 68:169-201 
Dannemiller JL. 2000. Competition in early exogenous orienting between 7 and 21 weeks. J. Exp. Child Psychol. 76:253-74

Dannemiller JL, Braun A. 1988. The perception of chromatic figure-ground relationships in 5-month-olds. Infant Behav. Dev. 11:31-42

Dannemiller JL, Freedland RL. 1993. Motionbased detection by 14-week-old infants. Vis. Res. 33:657-64

Dannemiller JL, Nagata Y. 1995. The robustness of infants' detection of visual motion. Infant Behav. Dev. 18:371-89

Desimone RJ, Ungerleider LG. 1989. Neural mechanisms of visual processing in monkeys. In Handbook of Neuropsychology, Vol. 2, ed. F Boller, J Grafman, pp. 267-99. New York: Elsevier

Divac I, Wikmark R, Gade A. 1975. Spontaneous alternation in rats with lesions in the frontal lobes: an extension of the frontal lobe syndrome. Physiol. Psychol. 3:39-42

Doty RW. 1995. Brainstem influences on forebrain processes, including memory. In $\mathrm{Neu}$ robehavioral Plasticity: Learning, Development, and the Response to Brain Insults, ed. NE Spear, LP Spear, ML Woodruff, pp. 34970. Hillsdale, NJ: Erlbaum

Driver J, Baylis GC. 1998b. Attention and visual object segmentation. See Parasuraman 1998b, pp. 299-326

Duncan J, Humphreys GW. 1989. Visual search and stimulus similarity. Psychol. Rev. 96:433-58

Egly R, Driver J, Rafal R. 1994. Shifting attention between objects and locations: evidence from normal and parietal lesion subjects. J. Exp. Psychol.: Gen. 123:161-77

Elman JL, Bates EA, Johnson MH, KarmiloffSmith A, Parisi D, Plunkett K. 1996. Rethinking Innateness: A Connectionist Perspective on Development. Cambridge, MA: MIT Press

Fagan JF. 1971. Infants' recognition memory for a series of visual stimuli. J. Exp. Child Psychol. 11:244-50

Fantz RL. 1963. Pattern vision in newborn infants. Science 140:296-97
Fisher DF, Monty JW. 1981. Eye Movements: Cognition and Visual Perception. Hillsdale, NJ: Erlbaum

Freeseman LJ, Colombo J, Coldren JT. 1993. Individual differences in infant visual attention: discrimination and generalization of global and local stimulus properties. Child Dev. 64:1191-203

Frick JE, Colombo J. 1996. Individual differences in infant visual attention: recognition of degraded visual forms by 4-month-olds. Child Dev. 67:188-204

Frick JE, Colombo J, Allen JSR. 2000. The temporal sequence of global-to-local processing in 3-month-olds. Infancy 1:375-86

Frick JE, Colombo J, Saxon TF. 1999. Individual and developmental differences in disengagement of fixation in early infancy. Child Dev. 70:537-48

Friedman-Hill S, Robertson LC, Triesman A. 1995. Parietal contributions to visual feature binding: evidence from a patient with bilateral lesions. Science 269:853-55

Funahashi S, Bruce CJ, Goldman-Rakic PS. 1989. Mnemonic coding of visual space in the monkey's dorsolateral prefrontal cortex. J. Neurophysiol. 61:331-49

Funahashi S, Bruce CJ, Goldman-Rakic PS. 1990. Visuospatial coding in primate prefrontal neurons revealed by oculomotor paradigms. J. Neurophysiol. 63:814-31

Ganon EC, Swartz KB. 1980. Perception of internal elements of compound figures by onemonth-old infants. J. Exp. Child Psychol. 30:159-70

Gardner JM, Karmel BZ. 1981. Preferential looking at temporal frequencies by preterm infants. Child Dev. 52:1299-302

Gardner JM, Karmel BZ. 1984. Arousal effects on visual preferences in neonates. Dev. Psychol. 20:374-77

Gardner JM, Karmel BZ, Magnano CL. 1992. Arousal/visual preference interactions in high-risk neonates. Dev. Psychol. 28:821-30 Gardner JM, Lewkowicz DJ, Rose SA, Karmel BZ. 1986. Effects of visual and auditory stimulation on subsequent visual preferences in 
neonates. Int. J. Behav. Dev. 9:251-63

Gardner JM, Turkewitz G. 1982. The effect of arousal level on visual preferences in preterm infants. Infant Behav. Dev. 5:369-85

Gazzaniga MS, ed. 1995. The Cognitive Neurosciences. Cambridge, MA: MIT Press

Gerhardstein P, Renner P, Rovee-Collier C. 1999. The roles of perceptual and categorical similarity in colour pop-out in infants. $\mathrm{Br}$. J. Dev. Psychol. 17:403-20

Gerson EF. 1969. Dimensions of infant behavior in the first six months of life. Proc. Annu. Conv. Am. Psychol. Assoc. 4:269-70 (Abstr.)

Geva R, Gardner JM, Karmel BZ. 1999. Feeding-based arousal effects on visual recognition memory in early infancy. Dev. Psychol. 35:640-50

Ghim H-R. 1990. Evidence for perceptual organization in infants: perception of subjective contours by young infants. Infant Behav. Dev. 13:221-48

Gilmore RO, Johnson MH. 1995. Working memory in infancy: six-month-olds' performance on two versions of the oculomotor delayed response task. J. Exp. Child Psychol. 59:397-418

Girton MR. 1979. Infants' attention to intrastimulus motion. J. Exp. Child Psychol. 28:416-23

Goldberg MC, Maurer D, Lewis TL. 1997. Influence of a central visual stimulus on infants' visual fields. Infant Behav. Dev. 20:359-70

Graham FK, Berg KM, Berg WK, Jackson JC, Hatton HM, Kantowitz SR. 1970. Cardiac orienting response as a function of age. Psychonom. Sci. 19:363-65

Gray J. 1982. The Neuropsychology of Anxiety. Oxford, UK: Clarendon

Greenberg DJ, Weizmann F. 1971. The measurement of visual attention in infants: a comparison of two methodologies. J. Exp. Child Psychol. 11:234-43

Guitton HA, Buchtel HA, Douglas RM. 1985. Frontal lobe lesions in man cause difficulties in suppressing reflexive glances and in generating goal-directed saccades. Exp. Brain Res. 58:455-72
Hainline L. 1981. Eye movements and form perception in human infants. See Fisher \& Monty 1981, pp. 3-19

Hainline L. 1998. Summary and commentary: Eye movements, attention, and development. See Richards 1998, pp. 163-78

Hainline L, Lemerise E. 1982. Infants' scanning of geometric forms varying in size. $J$. Exp. Child Psychol. 33:235-56

Hainline L, Turkel J, Abramov I, Lemerise E, Harris C. 1985. Characteristics of saccades in human infants. Vis. Res. 24:1771-80

Harman C, Posner MI, Rothbart MK, ThomasThrapp L. 1994. Development of orienting to locations and objects in human infants. Can. J. Exp. Psychol. 48:301-18

Harris PL. 1973. Eye movements between adjacent stimuli: an age change in infancy. $\mathrm{Br}$. J. Psychol. 64:215-18

Harrison AA, Everitt BJ, Robbins TW. 1997a. Central 5-HT depletion enhances impulsive responding without affecting the accuracy of attentional performance: interactions with dopaminergic mechanisms. Psychopharmacology 133:329-42

Harrison AA, Everitt BJ, Robbins TW. 1997b. Doubly dissociable effects of selective median raphé lesions on performance on the five-choice serial reaction time test of attention in rats. Brain Behav. Res. 89:135-49

Harrison AA, Muir JL, Robbins TW, Everitt BJ. 1992. The effect of forebrain 5-HT depletion on visual attentional performance in the rat. J. Psychopharmacol. 236:A59 (Abstr.)

Hartshorn K, Rovee-Collier C, Gerhardstein P, Bhatt RS, Wondoloski TL, et al. 1998. The ontogeny of long-term memory over the first year-and-a-half of life. Dev. Psychobiol. 32:69-89

He ZJ, Nakayama K. 1995. Visual attention to surfaces in 3-D space. Proc. Natl. Acad. Sci. USA 92:11155-59

Hickey TL. 1977. Postnatal development of the human lateral geniculate nucleus: relationship to a critical period for the visual system. Science 198:836-38 
Hickey TL, Peduzzi JD. 1987. Structure and development of the visual system. In Handbook of Infant Perception, ed. L Cohen, P Salapatek, pp. 1-42. New York: Academic

Hood BM. 1993. Inhibition of return produced by covert shifts of visual attention in 6month-olds. Infant Behav. Dev. 16:245-54

Hood BM. 1995. Shifts of visual attention in the infant: a neuroscientific approach. In $\mathrm{Ad}$ vances in Infancy Research, ed. C RoveeCollier, L Lipsitt, 9:163-216. Norwood, NJ: Ablex

Hood BM, Atkinson J. 1993. Disengaging visual attention in the infant and adult. Infant Behav. Dev. 16:405-22

Hood BM, Willen JD, Driver J. 1998. Adult's eyes trigger shifts of visual attention in human infants. Psychol. Sci. 9:131-34

Hopkins B, Van Wulfften-Palthe T. 1985. Staring in infancy. Early Hum. Dev. 12:26167

Jackson JC, Kantowitz SR, Graham FK. 1971. Can newborns show cardiac orienting? Child Dev. 42:107-21

James W. 1890. The Principles of Psychology. New York: Dover

Jankowsky JJ, Rose SA. 1997. The distribution of attention in infants. J. Exp. Child Psychol. 65: $127-40$

Johnson MH. 1990. Cortical maturation and the development of visual attention in early infancy. J. Cogn. Neurosci. 16:405-22

Johnson MH. 1995a. The development of visual attention: A cognitive neuroscience perspective. See Gazzaniga 1995, pp. 735-47

Johnson MH. 1995b. The inhibition of automatic saccades in early infancy. Dev. Psychobiol. 28:281-91

Johnson MH. 1998. Developing an attentive brain. See Parasuraman 1998b, pp. 427-44

Johnson MH, Dziurawiec S, Ellis HD, Morton J. 1991a. Newborns' preferential tracking of face-like stimuli and its subsequent decline. Cognition 40:1-19

Johnson MH, Posner MI, Rothbart MK. 1991b. Components of visual orienting in early infancy: contingency learning, anticipatory looking, and disengaging. J. Cogn. Neurosci. 3:335-44

Johnson MH, Posner MI, Rothbart MK. 1994. Facilitation of saccades toward a covertly attended location in early infancy. Psychol. Sci. 5:90-93

Johnson MH, Tucker LA. 1996. The development and temporal dynamics of spatial orienting in infants. J. Exp. Child Psychol. 63:171-88

Karmel BZ, Gardner JM, Magnano CL. 1991. Attention and arousal in early infancy. In Newborn Attention: Biological Constraints and the Influence of Experience, ed. MJS Weiss, PR Zelazo, pp. 339-76. Norwood, NJ: Ablex

Kellman PJ, Spelke ES. 1983. Perception of partly occluded objects in infancy. Cogn. Psychol. 15:483-524

Koob GF. 1992. Dopamine, addiction, and reward. Semin. Neurosci. 4:139-48

Korner AF. 1972. State as variable, as obstacle, and as mediator of stimulation in infant research. Merrill-Palmer Q. 18:77-94

Korner AF, Grobstein R. 1966. Visual alertness as related to soothing in neonates: implications for maternal stimulation and early deprivation. Child Dev. 37:867-76

Korner AF, Thoman EB. 1970. Visual alertness in neonates as evoked by maternal care. J. Exp. Child Psychol. 10:67-78

Kreminitzer JP, Vaughan HG, Kurtzberg D, Dowling K. 1979. Smooth pursuit eye movements in the newborn infant. Child Dev. 50:442-48

Lansink JM, Mintz S, Richards JE. 2000. The distribution of infant attention during object examination. Dev. Sci. 3:163-70

Lansink JM, Richards JE. 1997. Heart rate and behavioral measures of attention in 6-, 9-, and 12-month-old infants during toy play. Child Dev. 68:610-20

Leahy RL. 1976. Development of preferences and processes of visual scanning in the human infant. Dev. Psychol. 12:250-54

Linnemayer SA, Porges SW. 1986. Recognition memory and cardiac vagal tone in 
6-month-old infants. Infant Behav. Dev. 9: $43-56$

Livingstone MS, Hubel DL. 1987. Psychophysical evidence for separate channels for the perception of form, color, movement, and depth. J. Neurosci. 7:3416-68

Madole KL, Oakes LM. 1999. Making sense of infant categorization: stable processes and changing representations. Dev. Rev. 19:26396

Marrocco RT, Davidson MC. 1998. Neurochemistry of attention. See Parasuraman 1998b, pp. 35-50

Matsuzawa M, Shimojo S. 1997. Infants' fast saccades in the gap paradigm and development of visual attention. Infant Behav. Dev. 20:449-55

Maurer D. 1983. The scanning of compound figures by young infants. J. Exp. Child Psychol. 15:437-48

Maurer D, Salapatek P. 1976. Developmental changes in the scanning of faces by young infants. Child Dev. 47:523-27

Milewski A. 1976. Infants' discrimination of internal and external pattern elements. J. Exp. Child Psychol. 22:229-46

Moray N. 1969. Attention: Selective Processes in Vision and Hearing. London: Hutchinson Educational

Moray N. 1993. Designing for attention. In Attention: Selection, Awareness, and Control, ed. AD Baddeley, L Weiskrantz, pp. 111-34. New York: Oxford Univ. Press

Morruzzi G, Magoun HH. 1949. Brain stem reticular formation and activation of the EEG. Electroencephalogr. Clin. Neurophysiol. 1:455-73

Moss MM, Colombo J, Mitchell DW, Horowitz FD. 1988. Neonatal behavioral organization and 3-month visual discrimination. Child Dev. 59:1211-20

Mundy PC. 1985. Compound-stimulus information processing by 3-month-old infants. J. Genet. Psychol. 146:357-65

Nagata Y, Dannemiller JL. 1996. The selectivity of motion-driven visual attention in infants. Child Dev. 67:2608-20
Nakayama K, Joseph J. 1998. Attention, pattern recognition, and pop-out in visual search. See Parasuraman 1998b, pp. 279-326

Nishiike S, Takeda N, Kubo T, Nakamura S. 1997. Neurons in rostral ventrolateral medulla mediate vestibular inhibition of locus coeruleus in rats. Neuroscience 77:21932

Oakes LM, Tellinghuisen DJ. 1994. Examining in infancy: Does it reflect active processing? Dev. Psychol. 30:748-56

Parasuraman R. 1998a. The attentive brain: issues and prospects. See Parasuraman 1998b, pp. 3-15

Parasuraman R. 1998b. The Attentive Brain. Cambridge, MA: MIT Press

Parasuraman R, Davies DR, eds. 1984. Varieties of Attention. San Diego: Academic

Parasuraman R, Warm JS, See JE. 1998. Brain systems of vigilance. See Parasuraman 1998b, pp. 221-56

Phillips AG, Pfaus JG, Blaha CD. 1991. Dopamine and motivated behavior. In The Mesolimbic Dopamine System: From Motivation to Action, ed. P Willner, J ScheelKruger, pp. 199-224. Chichester, UK: Wiley

Phillips JO, Finocchio DV, Ong L, Fuchs AF. 1997. Smooth pursuit in 1- to 4month-old human infants. Vis. Res. 37:300920

Pompeiano O, Manzoni D, Barnes CD. 1991. Responses of locus coeruleus neurons to labyrinth and neck stimulation. Progr. Brain Res. 88:411-34

Porges SW. 1976. Peripheral and neurochemical parallels of psychopathology: a psychophysiological model relating autonomic imbalance in hyperactivity, psychopathology, and autism. In Advances in Child Development and Behavior, ed. HW Reese, 11:3565. New York: Academic

Porges SW. 1992. Autonomic regulation and attention. See Campbell \& Hayne 1992, pp. 201-26

Posner MI. 1980. Orienting of attention. Q. J. Exp. Psychol. 32:3-25 
Posner MI. 1995. Attention in cognitive neuroscience: an overview. See Gazzaniga 1995, pp. 615-24

Posner MI, Cohen Y. 1980. Attention and the control of movements. In Tutorials in Motor Behavior, ed. GE Stelmach, J Requin, pp. 243-58. Amsterdam: North Holland

Posner MI, Cohen Y. 1984. Components of visual orienting. In Attention and Performance $X$, ed. H Bouma, DG Bowhuis, pp. 531-56. Hillsdale, NJ: Erlbaum

Posner MI, Petersen S. 1990. The attention system of the human brain. Annu. Rev. Neurosci. 13:25-42

Posner MI, Rafal RD, Choate LS, Vaughan J. 1985. Inhibition of return: neural basis and function. Cogn. Neuropsychol. 2:211-28

Posner MI, Rothbart MK. 1991. Attentional mechanisms in conscious experience. In The Neuropsychology of Consciousness, ed. AD Milner, MD Rugg, pp. 91-112. London: Academic

Posner MI, Rothbart MK. 1998. Summary and commentary: developing attentional skills. See Richards 1998, pp. 317-23

Prablanc C, Jennerod M. 1975. Corrective saccades: dependence on retinal reafferent signals. Vis. Res. 18:557-60

Pylyshyn Z, Burkell J, Fisher B, Sears C, Schmidt W, Trick L. 1994. Multiple parallel access in visual attention. Can. J. Exp. Psychol. 48:60-83

Quinn PC, Bhatt RS. 1998. Visual pop-out in young infants: convergent evidence and an extension. Infant Behav. Dev. 21:273-88

Quinn PC, Eimas PD. 1996. Perceptual organization and categorization in young infants. In Advances in Infancy Research, ed. CK Rovee-Collier, LP Lipsitt, 10:1-36. Norwood, NJ: Ablex

Rafal R, Robertson LC. 1995. The neurology of visual attention. See Gazzaniga 1995, pp. 625-48

Rajkowski J, Kubiak P, Aston-Jones G. 1994. Locus coeruleus activity in monkey: phasic and tonic changes are associated with altered vigilance. Brain Res. Bull. 35:607-16
Reed MA, Pien DL, Rothbart MK. 1984. Inhibitory self-control in preschool children. Merrill-Palmer Q. 30:131-47

Richards JE. 1985a. The development of sustained attention in infants from 14 to 26 weeks of age. Psychophysiology 22:409-16

Richards JE. 1985b. Respiratory sinus arrhythmia predicts heart rate and visual responses. Psychophysiology 22:101-9

Richards JE. 1987. Infant visual sustained attention and respiratory sinus arrhythmia. Child Dev. 58:488-96

Richards JE. 1988. Heart rate offset responses to visual stimuli in infants from 14 to 26 weeks of age. Psychophysiology 25:278-91

Richards JE. 1989a. Development and stability in visual sustained attention in 14-, 20-, and 26-week-old infants. Psychophysiology 26:422-30

Richards JE. 1989b. Sustained visual attention in 8-week-old infants. Infant Behav. Dev. 12: 425-36

Richards JE. 1994. Baseline respiratory sinus arrhythmia and heart rate responses during sustained visual attention in preterm infants from 3 to 6 months of age. Psychophysiology 31:235-43

Richards JE. 1997a. Effects of attention on infants' preference for briefly exposed visual stimuli in the paired-comparison recognition-memory paradigm. Dev. Psychol. 33:22-31

Richards JE. 1997b. Peripheral stimulus localization by infants: attention, age, and individual differences in heart rate variability. $J$. Exp. Psychol.: Hum. Percept. Perform. 23: 667-80

Richards JE, ed. 1998. Cognitive Neuroscience of Attention: A Developmental Perspective. Mahwah, NJ: Erlbaum

Richards JE. 2000a. Localizing the development of covert attention in infants with scalp event-related potentials. Dev. Psychol. 36: 91-108

Richards JE. 2000b. Cortical indices of saccade planning following covert orienting in 20week-old infants. Infancy. In press 
Richards JE, Casey BJ. 1991. Heart rate variability during attention phases in young infants. Psychophysiology 28:43-53

Richards JE, Casey BJ. 1992. Development of sustained visual attention in the human infant. See Campbell \& Hayne 1992, pp. 3060

Richards JE, Gibson TL. 1997. Extended visual fixation in young infants: look distributions, heart rate changes, and attention. Child Dev. 68:1041-56

Richards JE, Holley FB. 1999. Infant attention and the development of smooth pursuit tracking. Dev. Psychol. 35:856-67

Richards JE, Hunter SK. 1998. Attention and eye movement in young infants: neural control and development. See Richards 1998, pp. 131-62

Robbins TW. 1998. Arousal and attention: psychopharmacological and neuropsychological studies in experimental animals. See Parasuraman 1998b, pp. 189-220

Robbins TW, Everitt BJ. 1995. Arousal systems and attention. See Gazzaniga, 1995, pp. 70320

Robbins TW, Everitt BJ, Marston HM, Wilkinson J, Jones GH, Page KJ. 1989. Comparative effects of ibotenic acid- and quisqualic acid-induced lesions of the substantia nigra nominata on attentional function in the rat: further implications for the role of the cholinergic neurons of the nucleus basalis in cognitive processes. Behav. Brain Res. 35:221-40

Robertson LC. 1998. Visuospatial attention and parietal function: their role in object perception. See Parasuraman 1998b, pp. 257-78

Robertson LC, Triesman A, Friedman-Hill S, Grabowecky M. 1997. A possible connection between spatial deficits and feature binding in a patient with parietal damage. J. Cogn. Neurosci. 9:295-317

Rose SA, Feldman J. 1990. Infant cognition: individual differences and developmental continuities. See Colombo \& Fagen 1990, pp. 229-45

Rose SA, Feldman JF. 1995. Cognitive Continuity from Infancy: A Single Thread or a
Twisted Skein? Presented at Soc. Res. Child Dev., Indianapolis, IN

Rovee-Collier C, Bhatt RS, Chazin S. 1996. Set size, novelty, and visual pop-out in infancy. J. Exp. Psychol.: Hum. Percept. Perform. 22:1178-87

Rovee-Collier C, Hankins E, Bhatt R. 1992. Textons, visual pop-out effects, and object recognition in infancy. J. Exp. Psychol.: Gen. 121:435-45

Ruff HA. 1975. The function of shifting fixations in the visual perception of infants. Child Dev. 46:857-65

Ruff HA. 1986. Components of attention during infants' manipulative exploration. Child Dev. 57:105-14

Ruff HA. 1990. Individual differences in sustained attention during infancy. See Colombo \& Fagen 1990, pp. 247-70

Ruff HA, Capozzoli M, Dubiner K, Parrinello R. 1990. A measure of vigilance in infancy. Infant Behav. Dev. 13:1-20

Ruff HA, Capozzoli M, Saltarelli LM. 1996. Focused visual attention and distractibility in 10-month-old infants. Infant Behav. Dev. 19:281-93

Ruff HA, Capozzoli M, Saltarelli LM, Dubiner K. 1992a. The differentiation of activity in infants' exploration of objects. Dev. Psychol. 28:851-61

Ruff HA, Capozzoli M, Weissberg R. 1998. Age, individuality, and context as factors in sustained visual attention during the preschool years. Dev. Psychol. 34:45464

Ruff HA, Lawson KR. 1990. Development of sustained, focused attention in young children during free play. Dev. Psychol. 26:8593

Ruff HA, Rothbart MK. 1996. Attention in Early Development: Themes and Variations. New York: Oxford Univ. Press

Ruff HA, Saltarelli LM, Capozzoli M, Dubiner K. 1992b. The differentiation of activity in infants' exploration of objects. Dev. Psychol. 28:851-61

Sahakian BJ, Owen AM, Morantz NJ, Eagger 
SA, Boddington S, et al. 1993. Further analysis of the cognitive effects of tetrahydroaminoacridine THA in Alzheimer's disease: assessment of attentional and mnemonic function using CANTAB. Psychopharmacology 110:395-401

Salapatek P. 1975. Pattern perception and early infancy. In Infant Perception: From Sensation to Cognition, ed. L Cohen, P Salapatek, 2:133-248. New York: Academic

Salapatek P, Aslin RN, Simonson J, Pulos E. 1980. Infant saccadic eye movements to visible and previously visible targets. Child Dev. 51:1090-94

Sarter M. 1994. Neuronal mechanisms of the attentional dysfunctions in senile dementia and schizophrenia: two sides of the same coin? Psychopharmacology 114:539-50

Schiller PH. 1998. The neural control of visually guided eye movements. See Richards 1998, pp. 3-50

Schuerger RJ, Balaban CD. 1999. Organization of the coeruleo-vestibular pathway in rats, rabbits, and monkeys. Brain Res. Brain Res. Rev. 30:189-217

Shea SL, Aslin RN. 1990. Oculomotor responses to step-ramp targets by young human infants. Vis. Res. 30:1077-92

Simion F, Valenza E, Umiltà C, Dalla-Barba B. 1995. Inhibition of return in newborns is temporo-nasal asymmetrical. Infant Behav. Dev. 18:189-94

Simons K, ed. 1993. Early Visual Development, Normal and Abnormal. Oxford: Oxford Univ. Press

Slater A. 1997. Visual perception and its organisation in early infancy. In Infant Development: Recent Advances, ed. G Bremner, A Slater, pp. 31-53. Hove, UK: Psychol. Press Spelke ES, Breinlinger K, Macomber J, Jacobson K. 1992. Origins of knowledge. Psychol. Rev. 99:605-32

Spelke ES, Van de Walle G. 1993. Perceiving and reasoning about objects: insights from infants. In Spatial Representation: Problems in Philosophy and Psychology, ed. N Eilan, R McCarthy, pp. 132-61. Oxford: Blackwell
Stechler G, Latz E. 1966. Some observations on attention and arousal in the human infant. $J$. Am. Acad. Child Psychiatry 5:517-25

Tellinghuisen DJ, Oakes LM. 1997. Distractibility in infancy: the effects of distractor characteristics and type of attention. J. Exp. Child Psychol. 64:232-54

Thoman EB. 1990. Sleeping and waking states in infants: a functional perspective. $\mathrm{Neu}$ rosci. Biobehav. Rev. 14:93-107

Treiber F, Wilcox S. 1980. Perception of a "subjective" contour by infants. Child Dev. 51:915-17

Treisman AM, Gelade G. 1980. A feature integration theory of attention. Cogn. Psychol. 12:97-136

Treisman AM, Souther J. 1985. Search asymmetry: a diagnostic for preattentive processing of separable features. J. Exp. Psychol.: Gen. 114:285-310

Tronick E, Brazelton TB. 1975. Clinical uses of the Brazelton Neonatal Behavioral Assessment. In Exceptional Infant, Vol. 3. Assessment and Intervention, ed. BZ Friedlander, GM Sterritt, GE Kirk, pp. 137-56. New York: Brunner/Mazel

Ungerleider LG, Mishkin MM. 1982. Two cortical visual systems. In Analysis of Visual Behavior, ed. DJ Ingle, MA Goodale, RJW Mansfield, pp. 549-86. Cambridge, MA: MIT Press

Usher M, Cohen JD, Servan-Schreiber D, Rajkowski J, Aston-Jones G. 1999. The role of locus coeruleus in the regulation of cognitive performance. Science 283:549-54

Valenza E, Simion F, Umiltà C. 1994. Inhibition of return in newborn infants. Infant Behav. Dev. 17:293-302

Van Giffen K, Haith MM. 1984. Infant response to Gestalt geometric forms. Infant Behav. Dev. 7:335-46

Vecera SP, Rothbart MK, Posner MI. 1991. Development of spontaneous alternation in infancy. J. Cogn. Neurosci. 3:351-54

Von Hofsten C, Rosander K. 1997. Development of smooth pursuit tracking in young infants. Vis. Res. 37:1799-810 
Warburton DM. 1977. Stimulus selection and behavioral inhibition. In Handbook of Psychopharmacology, ed. LL Iversen, SD Iversen, SH Snyder, pp. 385-431. New York: Plenum

Watson RT, Valenstein E, Heilman KM. 1981. Thalamic neglect: possible role of the medial thalamus and nucleus reticularis in behavior. Arch. Neurol. 38:501-6

Webster MJ, Ungerleider LG. 1998. Neuroanatomy of visual attention. See Parasuraman 1998b, pp. 19-34
Werner LA, Gray L. 1998. Behavioral studies of hearing development. In Development of the Auditory System: Springer Handbook of Auditory Research, ed. EW Rubel, A Popper, R Fay, 5:12-79. New York: SpringerVerlag

Wolff PH. 1965. The development of attention in young infants. Ann. NY Acad. Sci. 118:815-30

Wolff PH. 1966. The causes, controls, and organization of behavior in the neonate. Psychol. Issue 5:7-11 